\title{
Raising Healthy Children: Age Five ${ }^{1}$
}

\author{
Claire Marie Fassett and Karla P. Shelnutt ${ }^{2}$
}

As you drop your daughter off on her first day of kindergarten, she turns around and waves goodbye to you before running off to meet with friends. This milestone brings changes and new experiences for both you and your child. Throughout this year, your child will continue to develop socially, mentally, and physically, so you will want to be prepared to guide her through this stage of life. This publication is designed to give you some information about each of these areas for your five year old. The guidelines discussed in this article are generalized to boys and girls around the age of 5 . However, every child develops at a different rate, so not everything in this article may apply to your child. If you have concerns about your child's development, contact your pediatrician.

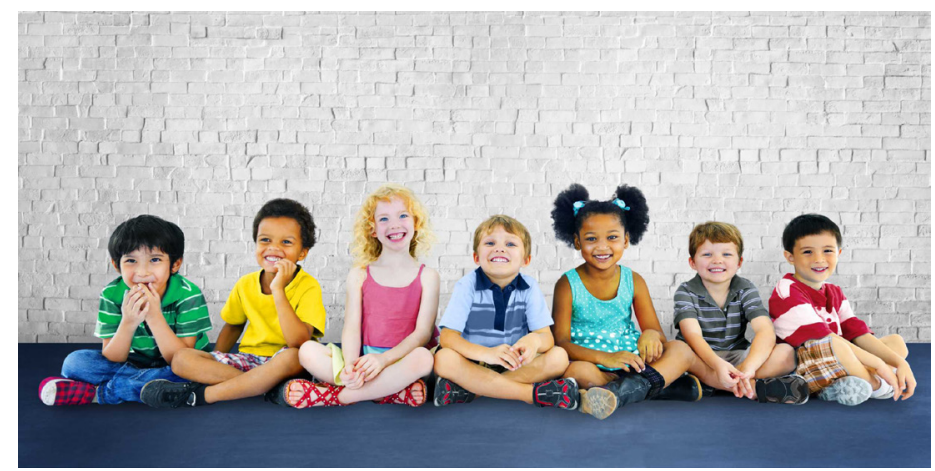

Figure 1. Making friends is a wonderful part of childhood and will help your child to develop socially.

Credits: Rawpixel Ltd/gettyimages.com

\section{Nutrition: MyPlate Daily Checklist}

Parents often worry about what and how much their child should be eating to meet her needs. To remove the guesswork from feeding a child, MyPlate (Figure 2) was designed to remind families which foods to eat and in what amounts. MyPlate has its own website located at www.choosemyplate.gov. This website includes a variety of resources and information related to healthy eating and physical activity. It even has games, activity sheets, videos, and songs designed to teach kids healthy habits in a fun and engaging way (USDA, 2016b).

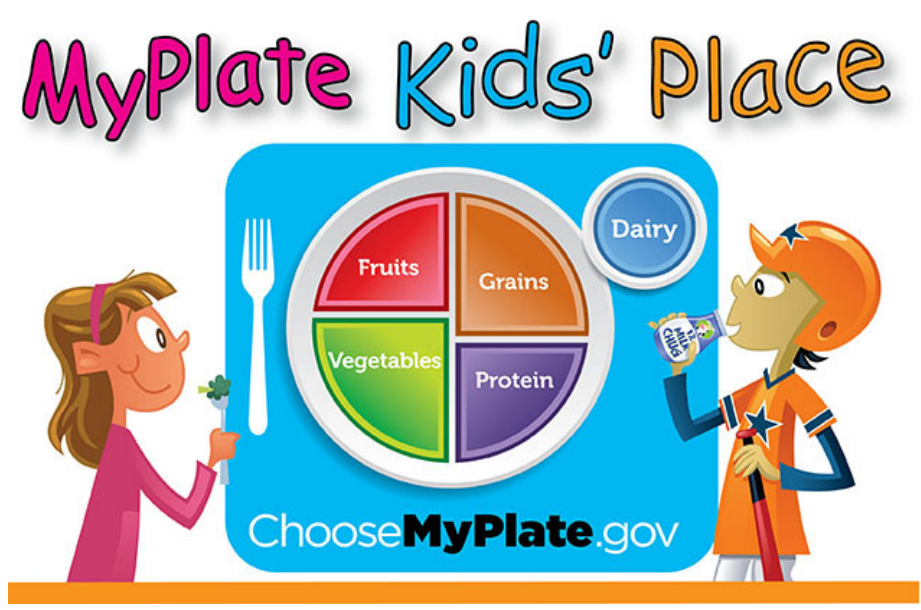

Figure 2. MyPlate is a great tool to use when determining portion sizes.

Credits: USDA

To ensure your child has a healthy eating style, refer to the MyPlate guidelines in Table 1. These recommendations are based on a 1,400-kcal diet, which is the recommended amount of calories for four- and five-year-old children who are active for 30-60 minutes per day. If your child's physical activity level falls outside of this range, her needs may be different for some food groups. If so, visit https://www.

1. This document is FCS3344, one of a series of the Department of Family, Youth and Community Sciences, UF/IFAS Extension. Original publication date January 2018. Visit the EDIS website at http://edis.ifas.ufl.edu.

2. Claire Marie Fassett, dietetic intern, Food Science and Human Nutrition Department; and Karla P. Shelnutt, associate professor, RDN, Department of Family, Youth and Community Sciences; UF/IFAS Extension, Gainesville, FL 32611. 
choosemyplate.gov/myplate-daily-checklist-preschoolers and select the calorie level that matches your child's daily physical activity to get a more accurate recommendation (USDA, 2016d). In addition, you can use MyPlate's SuperTracker to personalize recommendations based on your child's age, sex, height, weight, and physical activity level. To access the SuperTracker tool, visit www.SuperTracker. usda.gov (USDA, 2016e).

For more examples of recommended portions in each food group, visit https://www.choosemyplate.gov/MyPlate and select the food group of interest on the left side. For each food group, MyPlate provides a table of "What Counts" for the same recommended quantity (USDA, 2016a).

\section{Eating Behaviors}

When your child turns five, you may start to notice a few changes in her eating behaviors. Your child may begin to feel more comfortable eating without your supervision (USDA, 2016c). Use this higher level of independence as a chance to offer new foods to your child. Provide her with healthy meals and snacks at regular times, and then let your child choose how much to eat. It is important to sit down, eat, and enjoy meals with your child, not just feed her (Ellyn Satter Institute, 2016). Since children tend to mimic the behavior they see at home, it is important to be a positive role model for your child, especially during mealtime.

Being a positive role model for healthy eating habits is the best way to let your child maintain her new level of independence without making mealtime a conflict zone. Take the time to listen to your child's opinion of herself. Over the next couple of years, your child's body will undergo many changes. It is important to encourage your child to love her body at every stage. A study conducted on girls between the ages of 3 and 6 revealed that nearly $50 \%$ sometimes or always worried about being fat. When girls' opinions on fatness were examined, their reasons ranged from "being fat is bad" to "my mommy thinks she's fat" (Hayes \& TantleffDunn, 2010). Research has shown that words and phrases related to "fat talk" could lead to body dissatisfaction, low self-esteem, and altered eating behaviors (Shannon \& Mills, 2015). Try to avoid making negative comments about your own personal image, such as, "I can't believe how fat I look in that outfit." Children can easily pick up these statements and adopt these images about themselves. When parents engage in healthy thoughts and habits, it is more likely that their children will engage in them as well (Krisbergh, 2016).

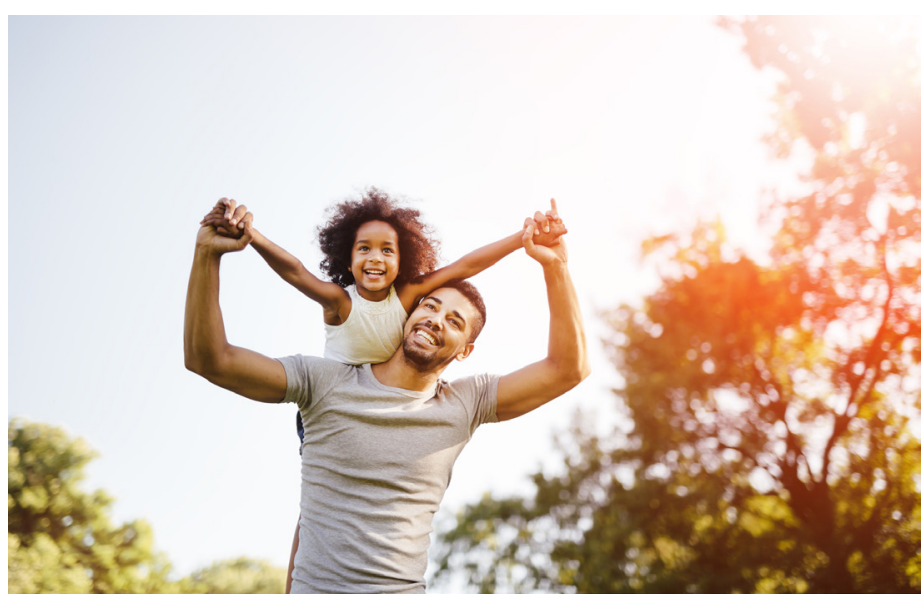

Figure 3. Being a positive role model and spending quality time with your child can help her be more confident in herself. Credits: nd3000/gettyimages.com

\section{Replacing Foods with Healthier Options}

By now, your child has tried a variety of foods and most likely has a "favorite food." If your child's favorite foods are not as healthy as other food options, try offering one new food at a time. However, always remember that the parent decides what to serve and when it is time for meals, while the child decides how much of a food item to eat.

Table 2 provides ideas for healthy substitutions that can be offered instead of favorite foods that are not as healthy.

\section{At Home: Helping in the Kitchen}

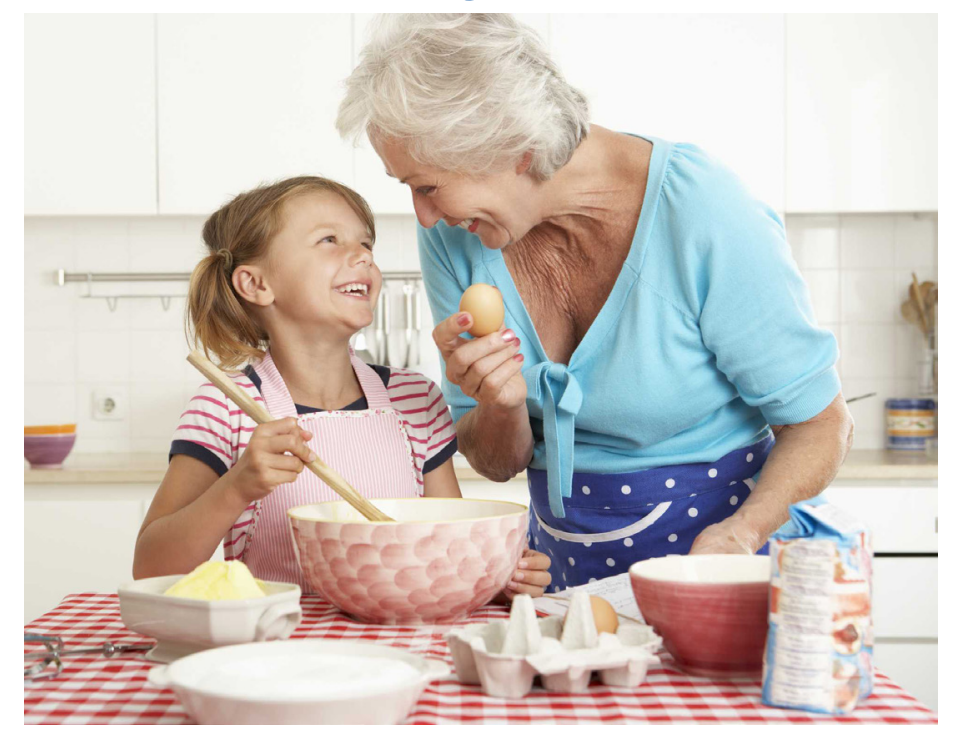

Figure 4. Children can help in the kitchen with safe cooking activities. Credits: bowdenimages/gettyimages.com

Show your child how much fun cooking healthy foods can be by letting her help in the kitchen. While it may take a little longer to get dinner on the table, it will teach your 
child valuable cooking skills she can use throughout her life. Research has shown that children are more likely to eat food when they are involved in its preparation (USDA, 2015b). It also provides a great opportunity to bond with your child. Here are some ways your five year old can help:

- Measure ingredients

- Use an egg beater

- Mix or pour ingredients

- Cut herbs with kid-safe scissors

- Mash foods, such as avocados, bananas, or beans, with a fork

- Cut shapes into soft sandwiches with cookie cutters

- Rinse small bowls and plates (National Heart, Lung, and Blood Institute, 2016)

\section{Physical Activity}

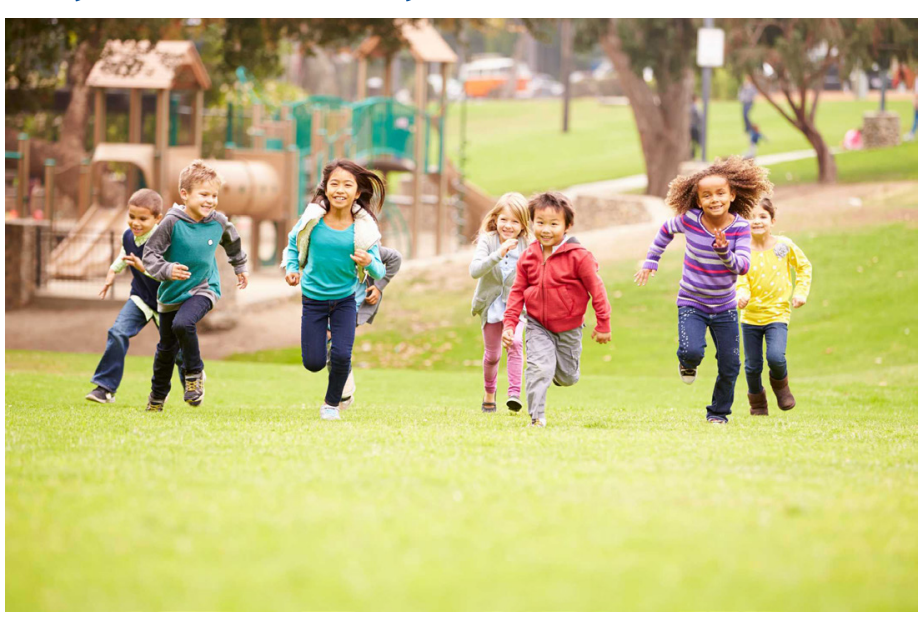

Figure 5. Playing with other children is a great way for your child to become more active.

Credits: bowdenimages/gettyimages.com

In addition to having a healthy eating style, five year olds should be physically active throughout the day. Their active time should be spread out in short bursts throughout the day rather than all at once. Your child may want to stay inside and watch TV or play games on the computer, but it is recommended that screen time be limited to less than two hours per day. Research has shown that too much screen time is linked to childhood obesity (Flores, 2008). After one hour of inactivity, encourage your child to be active again. Physical activity is also important for adults, so find ways to engage in fun, active games with your child. Below are a few ways you and your child can get exercise:

- Walk around the neighborhood

- Play catch

- Kick a ball
- Dance to music

- Play hide-and-seek

- Make and run an obstacle course (USDA, 2015a)

\section{Your Five Year Old and You}

As a parent, you play one of the most important roles in your child's development of healthy habits. Modeling a healthy eating style, having a positive body image, and engaging in physical activity will encourage your child to do the same (Krisbergh, 2016). There are many resources available to help you and your child be your healthiest. Some of these resources are:

- MyPlate: https://www.choosemyplate.gov/children

- SuperTracker: https://www.SuperTracker.usda.gov/

- American Academy of Pediatrics: https://www.healthychildren.org

\section{References}

Ellyn Satter Institute. (2016). 3 to 8 years: Feeding your preschooler/early school age child. Accessed on June 12, 2017. http://ellynsatterinstitute.org/htf/3to5years.php

Flores, A. (2008). New study correlates preschoolers' screen time with obesity. United States Department of Agriculture Agricultural Research Service. Accessed on January 5, 2017. https://www.ars.usda.gov/news-events/news/researchnews/2008/new-study-correlates-preschoolers-screen-timewith-obesity/

Hayes, S. \& Tantleff-Dunn, S. (2010). Am I too fat to be a princess? Examining the effects of popular children's media on young girls' body image. Br. J. Dev. Psychol. 28(2), 413-426. doi: 10.1348/026151009X424240.

Krisbergh, A. (2016). Being a role model-The promise and the peril. The Center for Parenting Education. Accessed on June 12, 2017. http://centerforparentingeducation.org/ library-of-articles/focus-parents/role-model-promise-peril/

National Heart, Lung, and Blood Institute. (2016). Getting kids in the kitchen. Parent Tips. Accessed on June 12, 2017. http://www.nhlbi.nih.gov/health/educational/wecan/ downloads/cookwithchildren.pdf

Shannon, A. \& Mills, J. (2015). Correlates, causes, and consequences of fat talk: A review. Body Image 15, 158-172. doi: 10.1016/j.bodyim.2015.09.003 
USDA. (2016a). Build a healthy eating style. MyPlate. Accessed on June 12, 2017. https://www.choosemyplate. gov/MyPlate

USDA. (2016b). ChooseMyPlate.gov. Accessed on June 12, 2017. http://choosemyplate.gov

USDA. (2016c). Health and nutrition information. ChooseMyPlate.gov. Accessed on June 12, 2017. https://www. choosemyplate.gov/health-and-nutrition-information

USDA. (2016d). MyPlate Daily Checklist for preschoolers. ChooseMyPlate.gov. Accessed on June 12, 2017. https://www.choosemyplate.gov/ myplate-daily-checklist-preschoolers

USDA. (2015a). Physical activity. ChooseMyPlate.gov. Accessed on June 12, 2017. https://www.choosemyplate. gov/preschoolers-physical-activity

USDA. (2015b). Picky eating. ChooseMyPlate.gov. Accessed on June 12, 2017. https://www.choosemyplate.gov/ preschoolers-picky-eating

USDA. (2016e). SuperTracker. Accessed on June 12, 2017. https://www.supertracker.usda.gov/ 
Table 1. Recommended amounts from each food group for a 1,400-kcal diet for a four- or five-year-old boy or girl who is active 30-60 minutes per day (USDA, 2016).

\begin{tabular}{|c|c|c|c|}
\hline Food Group & Recommended Amount & & Examples \\
\hline Fruits & $1 \frac{1}{2}$ cups & 1 cup $=$ & $\begin{array}{l}1 \text { cup } 100 \% \text { fruit juice } \\
1 \text { cup raw or cooked fruit } \\
1 / 2 \text { cup dried fruit }\end{array}$ \\
\hline Vegetables & $1 \frac{1}{2}$ cups & 1 cup $=$ & $\begin{array}{l}1 \text { cup raw or cooked vegetables } \\
2 \text { cups leafy greens (salad) } \\
1 \text { cup } 100 \% \text { vegetable juice }\end{array}$ \\
\hline Grains & 5 ounces & 1 ounce $=$ & $\begin{array}{l}1 \text { slice of bread } \\
1 \text { cup ready-to-eat cereal } \\
1 / 2 \text { cup cooked rice, pasta, or cereal }\end{array}$ \\
\hline Protein Foods & 4 ounces & 1 ounce $=$ & $\begin{array}{l}1 \text { slice of turkey } \\
1 \text { egg } \\
1 \text { tablespoon peanut butter } \\
1 / 2 \text { ounce nuts or seeds } \\
1 / 4 \text { cup cooked beans or peas }\end{array}$ \\
\hline Dairy & $2 \frac{1}{2}$ cups & 1 cup $=$ & $\begin{array}{l}1 \text { cup milk } \\
1 \text { cup yogurt } \\
1 \text { cup fortified soy beverage } \\
11 \frac{1}{2} \text { ounces natural cheese } \\
2 \text { ounces processed cheese }\end{array}$ \\
\hline
\end{tabular}

Table 2. Healthier food substitutions for common foods.

\begin{tabular}{|l|l|}
\hline Instead of... & Eat or Drink... \\
\hline French fries & Baked potato wedges \\
\hline Hamburger & Turkey burger \\
\hline Whole milk & Low-fat or fat-free milk \\
\hline Regular pancakes & Buckwheat pancakes \\
\hline Pre-baked toaster pastry & Peanut butter and apple slices on whole-wheat toast \\
\hline Spaghetti (white) with cheese sauce & Spaghetti squash with tomato sauce or whole-grain spaghetti with tomato sauce \\
\hline Butter or mayonnaise & Mashed avocado \\
\hline Gummy snacks & Dried fruit \\
\hline Fruit punch or fruit drink & $100 \%$ fruit juice \\
\hline Pizza & Whole-wheat crackers with melted low-fat cheese and sliced tomatoes \\
\hline
\end{tabular}

